\title{
GOVERNANÇA E REGULAÇÃO DOS SERVIÇOS PORTUÁRIOS: ESTUDO COMPARATIVO DOS SERVIÇOS DE PRATICAGEM EM PORTOS BRASILEIROS E ESPANHÓIS
}

\section{GOVERNANCE AND PORT SERVICES REGULATION: A COMPARISON BETWEEN BRAZILIAN AND SPANISH MARITIME PILOTAGE SERVICES}

\author{
Guilherme Bergmann Borges Vieira ${ }^{1}$; Luiz Afonso dos Santos Senna ${ }^{2}$; Francisco José Kliemann \\ Neto $^{3}$; Rafael Mozart da Silva ${ }^{4}$, Priscila Coutinho Costa ${ }^{5}$ \\ ${ }^{1}$ Universidade de Caxias do Sul (UCS) - Caxias do Sul - RS - Brasil \\ Universidade Federal do Rio Grande do Sul (UFRGS) - Porto Alegre - RS - Brasil \\ gbbvieir@ucs.br \\ ${ }^{2}$ Universidade Federal do Rio Grande do Sul (UFRGS) - Porto Alegre - RS - Brasil \\ lsenna@producao.ufrgs.br \\ ${ }^{3}$ Universidade Federal do Rio Grande do Sul (UFRGS) - Porto Alegre - RS - Brasil \\ kliemann@producao.ufrgs.br \\ ${ }^{4}$ Universidade Federal do Rio Grande do Sul (UFRGS) - Porto Alegre - RS - Brasil \\ rafmozart@terra.com.br \\ ${ }^{5}$ Universidade Federal do Rio Grande do Sul (UFRGS) - Porto Alegre - RS - Brasil \\ priscila.costa@ufrgs.br
}

\begin{abstract}
Resumo
Os portos são elementos-chave na rede global de transporte marítimo, sendo responsáveis pela interface terra-mar. Para a adequada gestão portuária, é necessária a compreensão do porto em um sentido mais amplo, considerando os diferentes atores que participam da cadeia logísticoportuária e as diversas atividades desenvolvidas no porto. Entre tais atividades, estão os serviços marítimos que antecedem a atracação dos navios nos portos e, particularmente, os serviços de praticagem, os quais são fundamentais para garantir a segurança e eficiência das operações portuárias e influenciam os custos de escala dos navios. Nos últimos anos, vêm se aprofundando a discussão sobre a adequação do modelo de praticagem brasileiro e sobre seu alinhamento com os modelos existentes em outros países. Nesse sentido, uma questão importante diz respeito à relação entre o modelo de praticagem adotado e os resultados obtidos, especificamente no que se refere aos preços dos serviços e à taxa de ocupação do sistema. Dado esse contexto, o presente estudo teve como objetivo analisar comparativamente os serviços de praticagem nos portos de Santos, Valência e Barcelona, tomando-se como base um modelo conceitual de análise da governança portuária e seguindo uma abordagem qualitativa-exploratória. Os resultados indicam que a falta de regulação econômica dos serviços de praticagem no Brasil tem acarretado preços elevados por manobra e baixa produtividade por prático no porto de Santos, o que se torna visivel mediante a comparação com os portos espanhóis estudados.
\end{abstract}

Palavras-chave: governança; serviços portuários; praticagem; portos brasileiros e espanhóis. 


\section{Introdução}

Nas últimas décadas, o comércio internacional tem crescido a taxas superiores às do crescimento econômico mundial. Segundo a Organização Mundial do Comércio (WTO, 2011), no período de 2000 a 2010 as exportações mundiais aumentaram 4,3\%, enquanto o PIB mundial cresceu 2,5\% e, especificamente no ano de 2010, o crescimento das exportações mundiais foi de 14\%, enquanto o PIB mundial cresceu 3,5\%. Além disso, segundo a United Nations Conference on Trade and Development (UNCTAD, 2011), uma grande porcentagem das operações de exportação e de importação concentra-se no modal marítimo, o qual representa mais de $80 \%$ das operações de comércio exterior. Daí a importância dos portos como elos de conexão terra-mar, influenciando a competitividade dos diferentes setores exportadores e importadores dos países e impactando na economia como um todo.

Segundo Bussinger (1998), pode-se considerar um porto sob três dimensões principais: i) como ente físico, o qual ocupa um espaço e possui fronteiras com outros ambientes naturais e urbanos - neste caso, tem-se como foco as instalações portuárias; ii) como agente econômico, tendo como foco as mercadorias, uma vez que os portos afetam o fluxo de comércio e o valor dos produtos que por eles passam, além de contribuirem para o desenvolvimento econômico das regiões em que estão situados; e iii) como elo de cadeias logísticas, tanto marítimas quanto terrestres, considerando diferentes origens, destinos e percursos, e tendo como foco as cargas e os processos logístico-portuários associados.

Dada essa terceira dimensão (os portos como elos de cadeias logísticas), a concepção moderna de gestão portuária deve considerar não apenas o porto em si, mas o contexto de toda a cadeia logístico-portuária, ou seja, o conjunto de atores e atividades realizadas no porto. Essas atividades podem ser localizadas no âmbito terrestre (movimentação, entrada e saída de contêineres), no âmbito marítimo (praticagem, rebocagem e atracação de navios) e na interface terra-mar (carga e descarga de navios).

No presente estudo, são estudadas as atividades portuárias no âmbito marítimo, mais especificamente os serviços de praticagem, os quais são fundamentais para garantir a segurança e a eficiência das operaçoes portuárias e têm um impacto considerável nos custos de escala dos navios. O estudo tem como objetivo analisar comparativamente os serviços de praticagem nos portos de Santos, Valência e Barcelona, visando verificar a relação entre o modelo de praticagem adotado e os resultados obtidos, especificamente no que se refere aos preços cobrados pelos serviços e à taxa de ocupação do sistema.

A justificativa do projeto baseia-se no fato de que, nos últimos anos, vem se aprofundando a discussão sobre a adequação do modelo de praticagem brasileiro e sobre seu alinhamento com os 
modelos existentes em outros países. Além disso, recentemente o governo criou a Comissão Nacional de Praticagem (CNAP) com o objetivo de estudar o tema e desenvolver uma metodologia de regulação econômica do setor.

A escolha dos portos de Santos, Valência e Barcelona para o estudo dos serviços de praticagem baseia-se em uma série de fatores. Em primeiro lugar, deve-se considerar a similaridade existente entre esses portos. Os portos de Santos, Valência e Barcelona estão todos sujeitos a um modelo de titularidade público federal e sua gestão pode ser explicada pelo modelo landlord, embora Valência e Barcelona já apresentem características que vão além desse modelo, já que desenvolvem ações para a coordenação dos atores da cadeia logístico-portuária que os aproximam do modelo 'landlord avançado' ou beyond the landlord (van der LUGT; DE LANGEN, 2007). Além disso, no que se refere à sua inserção na rede global de transporte marítimo, os três portos caracterizam-se como 'centros de cargas' ou load centres (DE LANGEN; van der LUGT; JOOST, 2002). A movimentação de cargas em portos desse tipo provém em grande medida de operações de exportação e de importação, sendo o transbordo menos significativo. Portanto, tais portos dependem tanto de suas conexões marítimas (vorland), no sentido de garantir abrangência e frequência adequadas em seus serviços de linha regular, quanto terrestres (hinterland), permitindo a obtenção de volumes apropriados de cargas de exportação e de importação. Dependem, também, da coordenação e eficiência dos diversos serviços portuários realizados nos âmbito terrestre e marítimo - e é neste ponto que se insere a praticagem. Outro ponto que justifica a comparação entre Santos, Valência e Barcelona é que os mesmos possuem volumes de serviço de praticagem comparáveis. No porto de Santos são realizadas anualmente cerca de 13.000 manobras de praticagem. Em Barcelona, o número de manobras é de aproximadamente 17.000 , cerca de $25 \%$ superior a Santos. E em Valência, são realizadas aproximadamente 15.000 manobras por ano, número 17\% inferior ao verificado em Santos.

A similaridade entre os três portos, discutida no parágrafo anterior, permite concluir que os mesmos são comparáveis. No entanto, também é importante destacar algumas diferenças existentes entre eles, o que justifica seu estudo comparativo. Nesse sentido, devem-se ressaltar três aspectos principais: i) o número de práticos muito inferior nos portos espanhóis, o que remete a uma maior taxa de ocupação do sistema; ii) o preço por manobra no porto brasileiro, significativamente superior; iii) o maior uso de tecnologias da informação aplicadas aos processos logístico-portuários nos portos de Valência e de Barcelona.

O trabalho foi desenvolvido mediante uma abordagem qualitativa-exploratória, baseada em entrevistas em profundidade realizadas com gestores portuários, visitas in loco nos três portos e pesquisa documental. 


\section{Os modelos de praticagem no contexto dos serviços portuários}

\subsection{Os serviços portuários}

Este capítulo apresenta as diferentes funções executadas pelos portos e sua relação com os modelos de gestão portuária, posicionando a praticagem nesse contexto. A Figura 1 apresenta o posicionamento dos serviços de praticagem no contexto da organização geral dos serviços portuários.

Figura 1 - Os serviços de Praticagem como parte do conjunto de serviços portuários

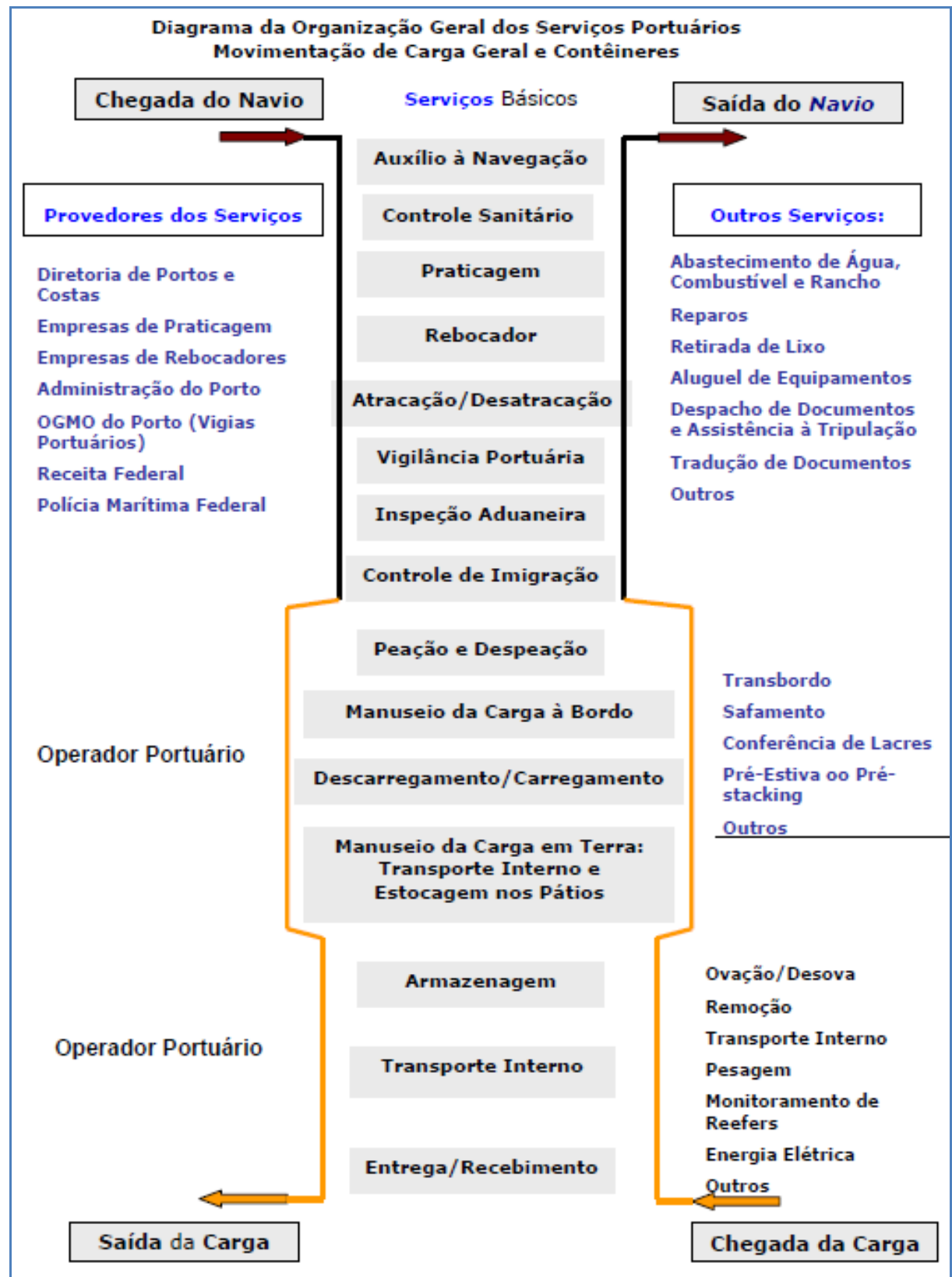


Percebe-se na Figura 1 que a praticagem é um serviço básico, prestado no momento da chegada ou saída dos navios dos portos. Em função disso, pode-se inferir que se trata de um serviço que impacta a eficiência dos portos, uma vez que influencia o uso dos berços de atracação durante certo período de tempo.

Brooks e Cullinane (2006) classificam as funções portuárias em quatro categorias: i) governança (coordenação); ii) regulação; iii) gestão e exploração dos espaços; e iv) operação. Os itens iii e iv seriam funções portuárias tradicionais, grande parte delas desenvolvidas localmente, pela própria Autoridade Portuária ou por terceiros - empresas públicas ou iniciativa privada. Já os itens i e ii correspondem a funções de coordenação e regulação do sistema portuário como um todo, que podem ser exercidas em nível federal, estadual ou municipal, conforme o caso, havendo maior ou menor autonomia da Autoridade Portuária, conforme o grau de centralização ou descentralização existente. A Figura 2 apresenta a classificação proposta por Brooks e Cullinane (2006).

Figura 2 - Classificação da praticagem

\begin{tabular}{|c|c|c|c|}
\hline \multirow[t]{2}{*}{ Governança } & \multirow[t]{2}{*}{ Regulação } & \multicolumn{2}{|c|}{ Funções portuárias } \\
\hline & & Landlord & Operator \\
\hline $\begin{array}{l}\text { Pública } \\
\text { Mista } \\
\text { Privada }\end{array}$ & $\begin{array}{l}\text { Concessões } \\
\text { Segurança da navegação } \\
\text { Aduana e imigração } \\
\text { Monitoramento do porto } \\
\text { Serviços de emergência } \\
\text { Proteção dos interesses públicos } \\
\text { em benefício da comunidade } \\
\text { Determinação das políticas } \\
\text { portuárias }\end{array}$ & $\begin{array}{l}\text { Manutenção dos acessos } \\
\text { marítimos (calado, } \\
\text { sinalização, etc.) } \\
\text { Desenvolvimento de } \\
\text { estratégias } \\
\text { Marketing portuário } \\
\text { Manutenção dos acessos } \\
\text { Segurança portuária } \\
\text { Aquisição e destinação dos } \\
\text { terrenos }\end{array}$ & $\begin{array}{l}\text { Atendimento aos navios } \\
\text { Manuseio de cargas } \\
\text { Praticagem e rebocagem } \\
\text { Manutençao e reparo de } \\
\text { equipamentos } \\
\text { Marketing de operações } \\
\text { portuárias } \\
\text { Destinação de resíduos } \\
\text { Desenvolvimento de berços de } \\
\text { atracação }\end{array}$ \\
\hline
\end{tabular}

Fonte: adaptada de Brooks e Cullinane (2006)

As funções portuárias apresentadas na Figura 2, segundo Brooks e Cullinane (2006), podem ser: i) de titularidade do governo central, bem como controladas e geridas pelo mesmo; ii) de titularidade do governo central, mas controladas e geridas por um órgão local (descentralizadas); iii) de titularidade do governo (federal, estadual ou municipal), mas controladas e geridas por uma entidade corporativa de direito privado; iv) de titularidade do governo central, mas geridas pela iniciativa privada via concessão ou arrendamento, ou mediante parcerias público-privadas (PPPs); e v) de titularidade privada, com o controle e a gestão exercidos pela iniciativa privada.

Segundo os autores, existe uma grande variabilidade na forma de alocação das funções portuárias. Ao analisarem 42 portos de diversas regiões e países, os autores identificaram a alocação mais usual para cada uma das funções, sendo que somente quatro portos apresentaram todas as funções desenvolvidas pelo setor público e apenas um operava sob um modelo totalmente privado. 
No caso da praticagem, que segundo a classificação proposta por Brooks e Cullinane (2006) é uma função associada à operação portuária (operator), há uma predominância de portos com esses serviços sob a titularidade, controle e gestão privados (categoria ' $\mathrm{v}$ ' apresentada anteriormente). Mais da metade dos portos da amostra enquadram-se nessa categoria. No entanto, também foram identificados portos com características que se enquadram nas categorias i e iii (pouco menos de $40 \%$ dos portos amostrados) e ii e iv (menos de $10 \%$ dos portos considerados no estudo).

Portanto, os serviços de praticagem se inserem nas funções portuárias - e estas no modelo de gestão portuário - de formas variadas. O importante é que o balanceamento entre a participação pública e privada nas funções portuárias apoie o desenvolvimento e a competitividade do porto (e dos setores que o utilizam), favorecendo o desenvolvimento econômico por meio da facilitação do comércio. Mas, obviamente, não há um modelo específico que sirva a diferentes portos ou sistemas portuários, uma vez que os mesmos desenvolveram-se de formas diferentes, seguindo distintas trajetórias e sujeitos a variadas influências históricas, econômicas, políticas, legais etc. Sendo assim, essa definição deve ser analisada cuidadosamente e é nesse contexto que devem ser considerados os serviços de Praticagem.

\subsection{O serviço de praticagem}

Uma cadeia logística pode ser estudada a partir de três tipos de fluxo: de mercadorias (ou contêineres), de informações e de capital (BEAMON, 1998). Referindo-se aos dois primeiros tipos de fluxo (mercadorias e informações), Monfort-Mulinas et al. (2012) afirmam que um terminal portuário é um sistema integrado com conexão física e de informação com as redes de transporte terrestre e marítima. Segundo os autores, esse sistema é composto por quatro subsistemas: i) carga e descarga de navios; ii) armazenamento de contêineres; iii) recepção e entrega terrestre; e iv) interconexão.

Este último subsistema tem como objetivo conectar o sistema de carga e descarga de navios com o de armazenamento, e o de armazenamento com o de recepção e entrega (MONFORTMULINAS et al., 2012). A Figura 3 apresenta de forma esquematizada a relação entre esses quatro subsistemas.

Figura 3 - Subsistemas de um porto de contêineres 


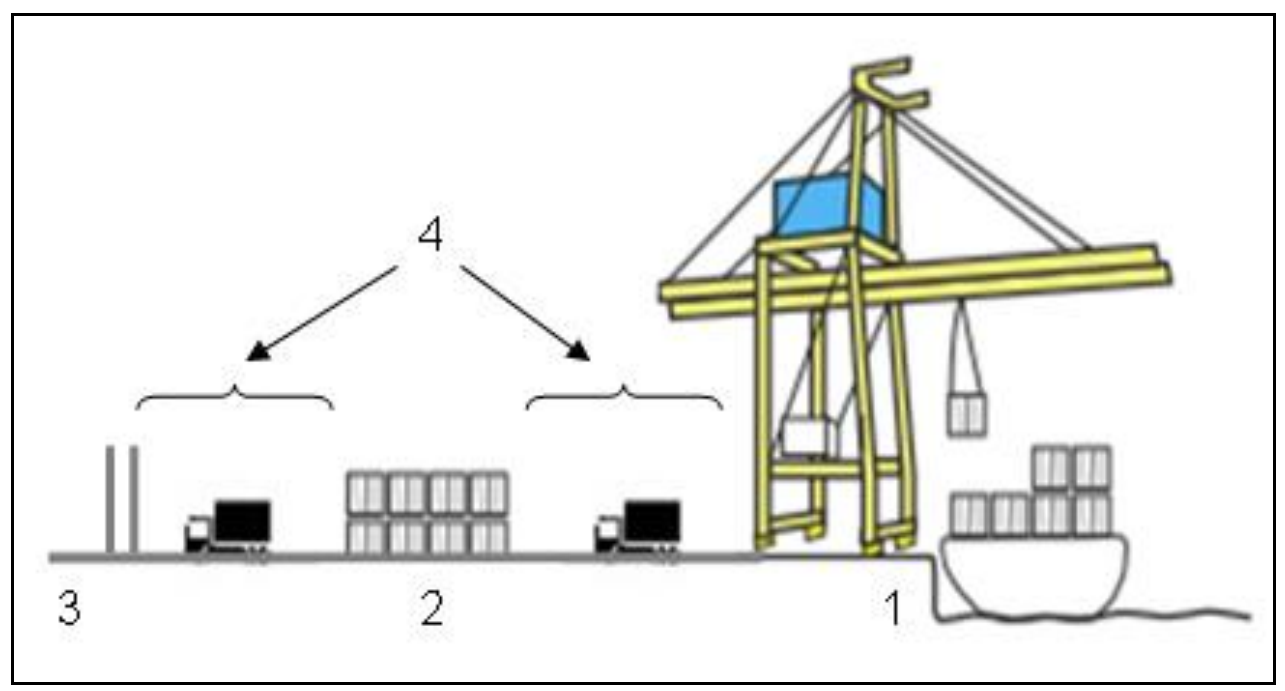

Fonte: adaptado de Monfort-Mulinas et al. (2012).

A gestão dos quatro subsistemas apresentados na Figura 3 impactam os fluxos logísticos em seu conjunto e, consequentemente, influenciam a competitividade dos setores exportadores e importadores que se utilizam do porto (MILAN; VIEIRA, 2011). Esse impacto se dá tanto pelo custo gerado a partir desses subsistemas quanto por sua influência no nível de serviço logístico.

A atividade de Praticagem é fundamental para a operação de um porto. Constitui-se na atividade de navegação e manobras de navios realizadas por profissionais habilitados (os Práticos) que possuem conhecimento das características locais como correntes, variações de marés, ventos e limitações dos pontos de acostagem, proporcionando maior eficiência e segurança à navegação. Esses profissionais atuam em trechos da costa, baías, portos, estuários de rios, lagos, rios, terminais e canais onde há tráfego de navios (CONAPRA, 2014). Essa atividade é realizada a bordo dos navios onde o Prático assessora o Comandante na condução segura da embarcação em áreas de navegação restrita ou sensíveis para o meio ambiente (CONAPRA, 2014).

Os serviços de Praticagem, dados os subsistemas apresentados anteriormente, antecedem o subsistema 1, podendo ter impacto direto sobre o mesmo. Por outro lado, tais serviços são um componente dos gastos de escala dos armadores (despesas incorridas nos diferentes portos de escala de determinada rota), podendo ter maior ou menor influência em tais gastos e impactando, em maior ou menor grau, os custos de operação do transporte marítimo como um todo. Obviamente, dadas as características do setor de transporte marítimo, especialmente o de linha regular (liner shipping - concentração do transporte mundial em um número reduzido de armadores e existência de variados acordos de cooperação entre eles - tais custos acabam sendo repassados aos fretes marítimos contratados por exportadores ou importadores - de acordo com a modalidade de venda (Incoterm) acordada entre eles - sendo, portanto, um elemento que afeta a competitividade dos setores que utilizam o porto. 


\subsection{Modelos de praticagem}

O serviço de praticagem apresenta como características mundialmente consagradas o caráter local; a concentração em uma única ou poucas empresas prestadoras de serviço; a ausência de vínculo empregatício; e o controle efetuado pelo Estado. Nesse contexto, podem-se classificar os modelos de praticagem em duas categorias principais (CEGN, 2008): i) serviço público prestado pelo Estado; e ii) serviço público prestado pelo setor privado, dividido em monopólios regulados e serviços abertos à livre iniciativa.

Os serviços de Praticagem estatais podem ser vinculados a autoridades portuárias públicas, ao poder executivo (governos e ministérios) ou à autoridade marítima. Já nos serviços privados, são dois os principais sistemas: i) sistema de monopólios regulados; e ii) sistema aberto à livre iniciativa. No primeiro, as associações prestam o serviço de forma exclusiva em uma área delimitada, com práticas e tarifas em geral reguladas, ao passo que no segundo não se impõem limites ao número de prestadores de serviço ou às tarifas praticadas por zona (CEGN, 2008). Dentre esses tipos de sistemas, predomina o caracterizado por monopólios regulados, que inclui Estados Unidos e a maioria dos países europeus. A livre iniciativa caracteriza o modelo argentino, o britânico e parte do australiano.

Como analisam Bonde et. al. (2000) apud CEGN (2008), a adoção de um modelo público ou privado depende principalmente da importância relativa dos custos da prestação do serviço e dos custos de transferência das atribuições do setor público ao privado (atividades legislativas, seleção, fiscalização etc.). À medida que o setor privado amplia sua participação, aumentam os custos de transferência, mas diminuem os de operação do serviço (CEGN, 2008). Isso porque, na maioria das empresas públicas, o regime de trabalho é com turnos fixos, o que o torna menos eficiente do que o de rodízio de serviço programado, aplicado nas associações de práticos autônomos.

Em vários países de economias estáveis, a forma com que os práticos se organizam é semelhante: associações únicas (ou mais de uma com rodízio único) com exclusividade sobre um local e sob forte controle público.

No caso brasileiro, o serviço de praticagem está submetido à supervisão e normatização da Autoridade Marítima. O marco legal da atividade é a Lei 9.537 - Lei de Segurança do Tráfego Aquaviário (LESTA) de 1997, regulamentada pelo Decreto 2.596 de 1998 (RLESTA). O documento que normatiza a Praticagem é a NORMAN 12, emitida e revista periodicamente pela Diretoria de Portos e Costas da Marinha do Brasil (DPC).

A legislação brasileira sobre Praticagem estabelece diretrizes para o serviço de Praticagem em águas jurisdicionais brasileiras, posto que é atribuição da Autoridade Marítima (DPC), entre 
outras, "regulamentar o serviço de Praticagem, estabelecer as zonas de Praticagem em que a utilização do serviço é obrigatória e especificar as embarcações dispensadas do serviço".

O serviço de Praticagem é constituído pelo conjunto de prático, lancha de prático e atalaia. A lancha de prático é a embarcação homologada pelo Capitão dos Portos com jurisdição sobre a zona de Praticagem para ser empregada no transporte do prático para o embarque/ desembarque nos e dos navios; já a atalaia é definida como "estrutura operacional e administrativa, homologada pelo Órgão Nacional de Praticagem, com a capacidade de prover, coordenar, controlar e apoiar o atendimento do Prático aos navios dentro de uma ZP, nas manobras de entrada e saída dos portos e terminais e nas singraduras dentro da ZP, possibilitando a disponibilidade ininterrupta e o desempenho eficiente do Serviço de Praticagem”. Por fim, a ZP é a área geográfica delimitada pelo Diretor de Portos e Costas, dentro da qual se realizam os serviços de Praticagem. Como o serviço de Praticagem é legalmente considerado atividade essencial, devendo estar permanentemente disponível nas zonas de Praticagem estabelecidas, a Autoridade Marítima tem a prerrogativa de: i) estabelecer o número de práticos necessário para cada zona de Praticagem; ii) fixar o preço do serviço em cada zona de Praticagem; e iii) requisitar o serviço de práticos.

Todavia, apesar da prerrogativa dada à Autoridade pela Lei, o RLESTA estabelece que o preço do serviço de praticagem deve ser livremente negociado entre as partes interessadas e que, somente em caso de excepcionalidade, não havendo acordo entre as partes, a Autoridade Marítima determinará a fixação do preço, garantida a obrigatoriedade da prestação do serviço. Portanto, quanto à definição de preços, o Brasil difere de países em que há regulação econômica dos serviços. No caso brasileiro, os preços não são fixados por uma autoridade, mas negociados diretamente entre as associações de práticos e os armadores. Cada associação tem autonomia, prevista em lei, para negociar suas próprias tarifas. Caso não haja acordo, a autoridade marítima, como agente do Estado, deve fixar preços e exigir a prestação do serviço (CEGN, 2008). Do ponto de vista econômico e de regulação, a obrigatoriedade do uso dos serviços de praticagem e a oferta limitada caracterizam um mercado com características monopolísticas. Dado esse contexto, a praticagem tem sido objeto de análise da recém criada Comissão Nacional para Assuntos de Praticagem (CNAP), com vistas a estabelecer uma regulação econômica para o setor. Na pauta das discussões da recém criada CNAP estão a definição dos preços máximos, a taxa de ocupação do sistema e a qualidade dos serviços prestados, entre outras questões.

\section{Modelo de governança portuária aplicado aos serviços de praticagem}

Uma vez que as atividades do porto são afetadas por diversos atores, a governança portuária pode ser entendida como as relações existentes entre esses atores e os mecanismos de coordenação utilizados (DE LANGEN, 2004). Segundo De Langen, Nijdam e van der Horst (2007), essa 
coordenação pode levar a portos e cadeias logísticas mais eficientes. Assim, a governança trata-se de um fator-chave tanto para a competitividade do porto e sua consequente inserção nas redes globais de transporte marítimo, considerando-se uma lógica funcional, quanto para o desenvolvimento da região em que o mesmo está inserido, considerando-se uma abordagem territorial.

Em que pese a importância do tema, os estudos sobre governança portuária são recentes, tendo sido realizados em sua maior parte a partir da segunda metade da década de 2000. Da mesma forma que na pesquisa portuária como um todo, no estudo da governança portuária têm sido mais utilizadas abordagens qualitativas, baseadas em estudos de caso e em trabalhos conceituais. Segundo Pallis (2007), tais estudos têm abordado os princípios e instituições pelas quais a autoridade é exercida, bem como os processos pelos quais os portos selecionam, monitoram e redefinem as suas estratégias e as capacidades das pessoas em posição de autoridade para efetivamente gerir os recursos portuários, implementar políticas e governar as interações econômicas entre os atores.

Grande parte desses estudos aborda o tema da estrutura de governança, desenvolvendo modelos conceituais de governança (WORLD BANK, 2001; WANG; NG; OLIVIER, 2004; BALTAZAR; BROOKS, 2006; BROOKS; CULLINANE, 2006; DEBRIE; GOUVERNAL; SLACK, 2007; PALLIS, 2007; BROOKS; PALLIS, 2008) e testando empiricamente sua adequação em diversos países, tais como Estados Unidos (FAWCETT, 2006), Holanda (DE LANGEN; van der LUGT, 2006), Bélgica (MEERSMAN; van de VOORDE; VANELSLANDER, 2006), China (CULLINANE; WANG, 2006), Grécia (PALLIS, 2006) e Canadá (BROOKS, 2006; DEBRIE; GOUVERNAL; SLACK, 2007), e em portos como Roterdã (DE LANGEN, 2006), Singapura (CULLINANE; YAP; LAM, 2006) e Hamburgo (FLÄMIG; HESSE, 2011), entre outros.

Segundo Geiger (2009), um modelo de governança deve responder a três perguntas básicas: i) Quem governa? ii) O que governa? e iii) Como governa? As respostas a essas perguntas definem: i) a estrutura de governança; ii) os elementos de governança; e iii) as ações de governança. Além dessas questões, Vieira, Kliemann Neto e Monfort-Mulinas (2013) propuseram uma anterior: Para que governa? Essa pergunta tem relação com os resultados desejáveis da governança, tais como o aumento da eficiência e a inserção competitiva do porto. Baseados nessas quatro questões, Vieira, Kliemann Neto e Monfort-Mulinas (2013) desenvolveram um modelo conceitual de governança, o qual serve como uma estrutura de referência para apoiar a análise da governança portuária em suas principais dimensões (resultados, estrutura, elementos e ações) e pode ser aplicado aos serviços de praticagem. $\mathrm{O}$ arcabouço conceitual do referido modelo é apresentado na Figura 4.

Figura 4 - Arcabouço conceitual do modelo de governança de cadeias logístico-portuárias 


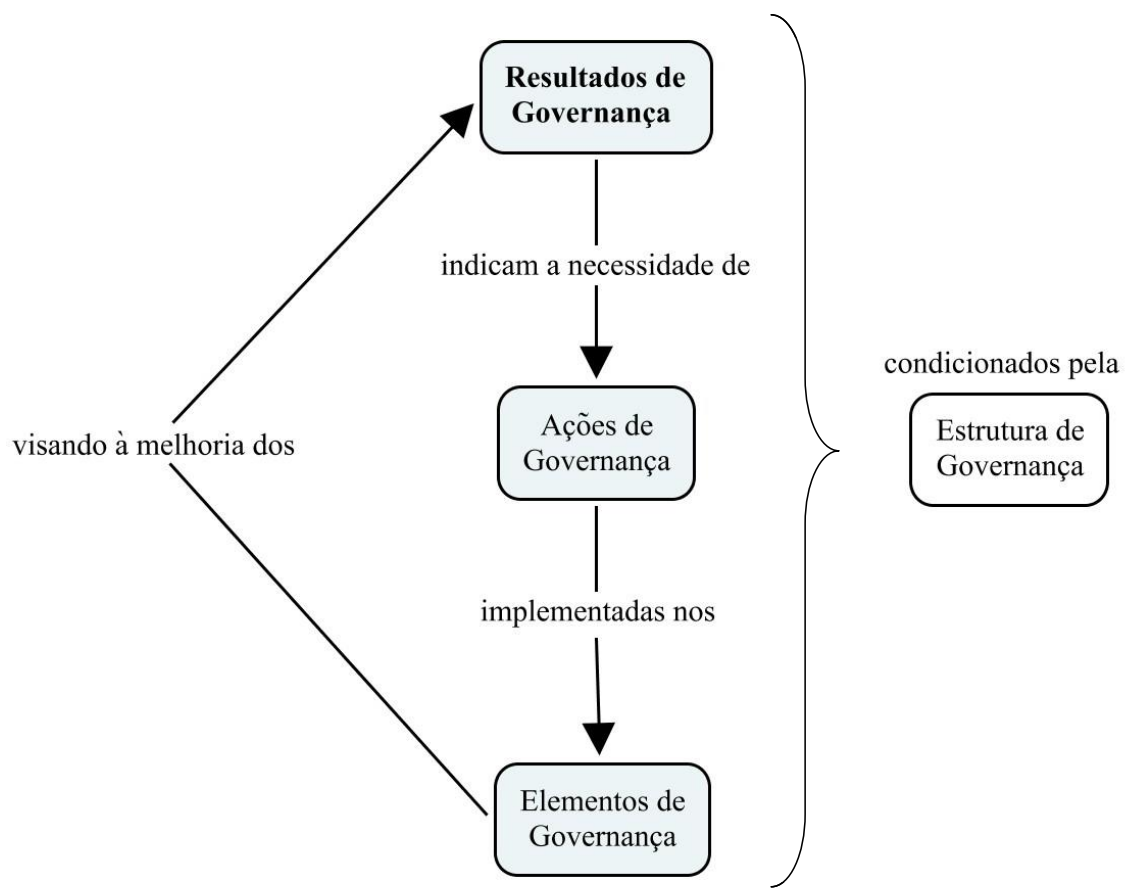

Fonte: Vieira, Kliemann Neto e Monfort-Mulinas (2013)

A lógica do modelo é de que os resultados de governança (para que governa) indicam a necessidade de ações de governança (como governa), visando aumentar a integração dos atores cadeia logístico-portuária e a eficiência dos fluxos associados, que são os elementos de governança (o que governa), tudo isso condicionado pela estrutura de governança existente (quem governa). A partir do modelo proposto por Vieira, Kliemann Neto e Monfort-Mulinas (2013), tem-se uma lógica abrangente e estruturada para orientar a governança e a regulação dos serviços de praticagem.

\section{Procedimentos metodológicos}

Conforme Marconi e Lakatos (2002), a pesquisa pode ser entendida como um procedimento formal, com método de pensamento reflexivo, que requer um tratamento científico e se constitui no caminho para se conhecer a realidade ou para descobrir verdades parciais. Na Figura 5, apresenta-se a estrutura metodológica utilizada para o desenvolvimento deste projeto.

Figura 5 - Estrutura da metodologia de pesquisa 


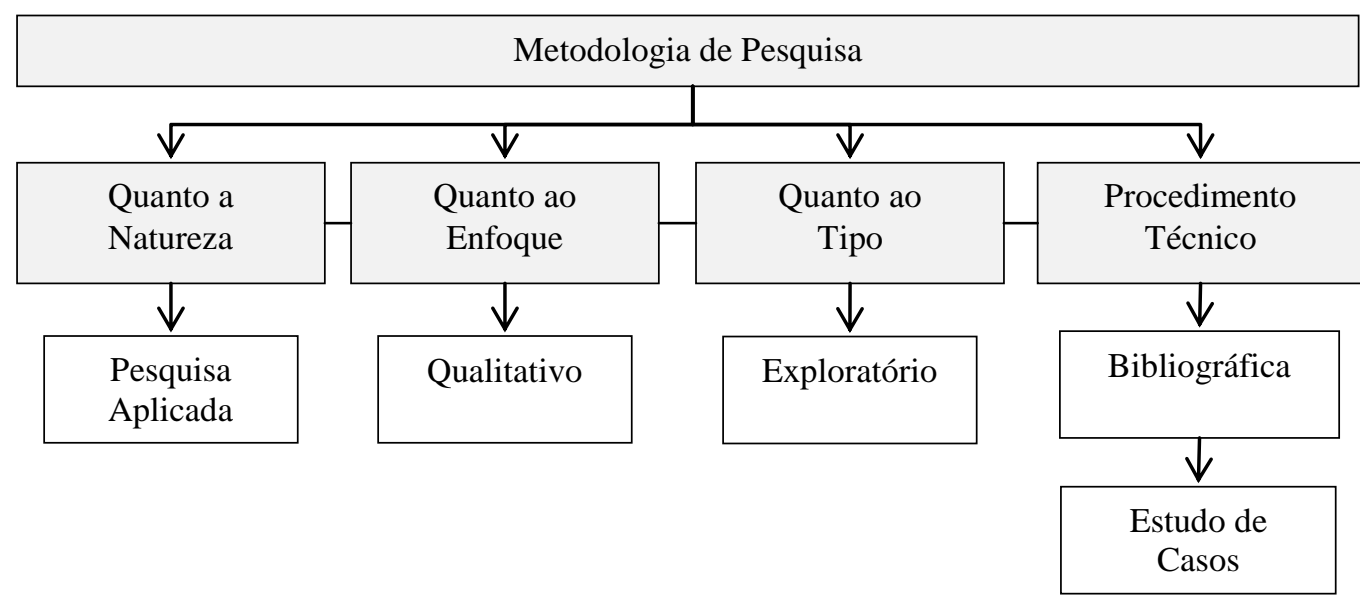

Quanto ao enfoque, as pesquisas podem ser classificadas como: i) quantitativas; ii) qualitativas; iii) de duas etapas (qualitativa e quantitativa ou vice-versa); iv) de enfoque dominante (qualitativo ou quantitativo); e v) de enfoque misto, combinando as duas abordagens (SAMPIERI; COLLADO; LUCIO, 2006). E, quanto ao tipo, podem ser classificadas como: i) exploratórias, que investigam um tema emergente ou pouco estudado; ii) descritivas, que visam descrever (qualitativa ou quantitativamente) as características de qualquer fenômeno ou objeto sujeito à análise; iii) correlacionais, que visam analisar a relação entre duas ou mais variáveis; e iv) explicativas, que objetivam desvendar as causas dos fenômenos estudados.

O presente projeto pode ser classificado: i) quanto à natureza, como uma pesquisa aplicada; ii) quanto ao enfoque, como um estudo qualitativo; e iii) quanto ao tipo, como exploratório. De acordo com Silva e Menezes (2005), uma pesquisa aplicada objetiva gerar conhecimentos para aplicação prática dirigidos à solução de problemas específicos, envolvendo verdades e interesses locais. Segundo Skinner, Tagg e Holloway (2000), as pesquisas qualitativas focam a experiência das pessoas e o significado de eventos, processos e estruturas inseridos em cenários sociais. Normalmente, estudos desse tipo utilizam-se de amostras pequenas e estatisticamente não representativas e têm por objetivo conhecer relações gerais, refinar conceitos e identificar oportunidades de melhoria (HELLEBUSCH, 2000). Já os estudos de natureza exploratória visam tornar o problema mais explícito (GIL, 1999; MARCONI; LAKATOS, 2002), sendo recomendados especialmente nos casos em que há pouco conhecimento disponível sobre o assunto (CERVO; BERVIAN, 2002).

Inicialmente, foi realizado um levantamento do referencial teórico sobre governança e regulação de serviços portuários, tendo como foco os serviços de praticagem. A partir da revisão da literatura, foi realizado um estudo comparativo dos serviços de praticagem nos portos de Santos, Valência e Barcelona, combinando dados primários, obtidos mediante entrevistas em profundidade e observações in loco, e dados secundários, disponíveis em órgaos do setor marítimo-portuário. 
A análise foi realizada em duas etapas. Primeiramente, foram analisados os modelos de praticagem existentes nos portos do Brasil (Santos) e da Espanha (Valência e Barcelona) no que refere à regulação técnica (segurança das manobras e normas de acesso à profissão) e econômica (definição dos preços das manobras). A seguir, foi feita uma parametrização de aspectos operacionais relacionados com o serviço, especialmente no que diz respeito ao grau de ocupação e produtividade dos práticos e aos preços cobrados pelas manobras. Para tanto, foram considerados: como inputs, o número de práticos existentes em 2012 em cada porto, o número de manobras realizadas nesse mesmo ano, o porte médio dos navios (arqueação bruta média) e o tempo médio das manobras; e como outputs o número de manobras por prático (por ano, por mês e por dia) e os preços médios por manobra e por hora de manobra.

\section{Resultados}

Neste capítulo são apresentados os resultados obtidos no estudo, sendo analisados os modelos de praticagem existentes nos portos do Brasil (Santos) e da Espanha (Valência e Barcelona) e sendo feita uma parametrização de aspectos operacionais relacionados com o serviço, considerando-se principalmente o grau de ocupação e produtividade dos práticos e os preços cobrados pelas manobras.

\subsection{Modelo de praticagem existente: regulação técnica e econômica}

A Figura 6 apresenta uma comparação entre os atores responsáveis pela regulação técnica e econômica dos serviços de praticagem no Brasil e na Espanha.

Figura 6 - Aspectos básicos da regulação técnica e econômica

\begin{tabular}{|l|l|l|}
\hline Porto & Regulação técnica $(R T)$ & Regulação econômica $(R E)$ \\
\hline Santos & Autoridade Marítima (Diretoria de Portos e Costas) & Inexistente \\
Valência & Autoridade Marítima (Salvamento Marítimo) & Autoridade Portuária \\
Barcelona & Autoridade Marítima (Salvamento Marítimo) & Autoridade Portuária \\
\hline
\end{tabular}

Percebe-se certa similaridade no que se refere ao ator responsável pela regulação técnica dos serviços de praticagem nos dois países (Autoridade Marítima). Por outro lado, chama a atenção a falta de clareza quanto ao ator responsável pela regulação econômica dos serviços de praticagem no Brasil (na Espanha, isso fica a cargo das Autoridades Portuárias). Apesar da prerrogativa de fixação do preço dos serviços de praticagem dada no Brasil à Autoridade Marítima pela Lei de Segurança do Tráfego Aquaviário (LESTA), o regulamento dessa Lei - Regulamento da Lei de Segurança do Tráfego Aquaviário (RLESTA) - estabelece que o preço do serviço de praticagem deve ser livremente negociado entre as partes interessadas e que, somente em caso de excepcionalidade, não havendo acordo entre as partes, a Autoridade Marítima determinará a fixação do preço, garantida a obrigatoriedade da prestação do serviço. Portanto, quanto à definição de preços, o Brasil difere da 
Espanha, uma vez que não há fixação de preços máximos por uma autoridade. No caso espanhol, os preços máximos dos serviços de praticagem são fixados localmente por cada Autoridade Portuária, segundo prerrogativa dada pela Lei de Portos; no Brasil, os mesmos são negociados diretamente entre as associações de práticos e os armadores, com a Autoridade Marítima intervindo somente quando não houver acordo entre as partes. Cabe salientar que essas intervenções da Autoridade Marítima na fixação de preços acabam por manter possíveis distorções decorrentes de abuso de poder de mercado, uma vez que os preços são determinados mediante simples aplicação de um indexador aos preços anteriormente praticados.

A Figura 7, por sua vez, apresenta os principais aspectos do modelo de governança dos serviços de praticagem no Brasil (porto de Santos) e na Espanha (portos de Valência e de Barcelona), considerando o modelo proposto por Vieira, Kliemann Neto e Monfort-Mulinas (2013), o qual visa responder a quatro questões-chave: i) Quem governa? ii) O que governa? iii) Como governa? e iv) Para que governa?

No Brasil não há orgão responsável pela regulação econômica do serviço de praticagem, diferentemente do que é visto na Espanha, onde a Autoridade Portuária publica suas tarifas vigentes em conformidade com a Lei de Portos. Quanto à regulação técnica, os dois países possuem algumas características semelhantes: ambos possuem orgãos regulamentadores e que determinam o acesso a profissão, a qualificação dos práticos e a segurança desse serviço, entre outros aspectos. Além disso, as leis que regem esse serviço são relativamente análogas, sendo a LESTA, o RLESTA e a NORMAM 12 equivalentes à Lei da Marinha Mercante da Espanha e a Lei de Portos espanhola quando abordam assuntos referentes à praticagem. No entanto, as leis espanholas reconhecem a competência das autoridades portuárias para a regulação dos serviços de praticagem. Na Lei de Portos brasileira o termo praticagem não é sequer mencionado. Dessa forma, de acordo com a LESTA, a responsabilidade sobre o serviço de praticagem no Brasil é atribuida à Marinha, que assume compromisso com a segurança em águas jurisdicionais brasileiras. Contudo, a competência quanto à regulação econômica dos serviços, definida pela LESTA e pelo RLESTA, é controversa. O governo entende que o artigo 14 da LESTA confere à Autoridade Marítima competencia para regular economicamente o setor. No entanto, tal fato tem sido contestado pelos práticos, inclusive judicialmente, tomando como base o que é definido no RLESTA, de que "o preço do serviço de praticagem deve ser livremente negociado entre as partes interessadas e que, somente em caso de excepcionalidade, não havendo acordo entre as partes, a Autoridade Marítima determinará a fixação do preço, garantida a obrigatoriedade da prestação do serviço".

Figura 7 - Modelo de governança do serviço de praticagem no Brasil e na Espanha

\begin{tabular}{|l|l|l|}
\hline Questão-chave & Espanha (Valência e Barcelona) & Brasil (Santos) \\
\hline Quem governa & RT: Salvamento Marítimo & RT: Diretoria de Portos e Costas \\
& RE: Autoridade Portuária & RE: Inexistente \\
\hline
\end{tabular}




\begin{tabular}{|c|c|c|}
\hline O que governa & $\begin{array}{l}\text { RT: Acesso à profissão, qualificação dos } \\
\text { profissionais, segurança, qualidade e } \\
\text { preços dos serviços } \\
\text { RE: Número de práticos e preços máximos } \\
\text { dos serviços por tipo de navio (AB) }\end{array}$ & $\begin{array}{l}\text { RT: Acesso à profissão, número de práticos, } \\
\text { qualificação dos profissionais, manutenção dos } \\
\text { registros, condições básicas para a realização dos } \\
\text { serviços, segurança da navegação } \\
\text { RE: Inexistente }\end{array}$ \\
\hline Como governa & $\begin{array}{l}\text { RT: Lei de Portos (definição e } \\
\text { características do serviço de praticagem, } \\
\text { regime de gestão, proteção do pessoal de } \\
\text { praticagem, rodízio de práticos, } \\
\text { responsabilidade dos práticos, prazo } \\
\text { máximo de licença para a prestação dos } \\
\text { serviços de praticagem em cada porto) e } \\
\text { Lei da Marinha Mercante (zonas de } \\
\text { praticagem obrigatória, requisitos } \\
\text { profissionais, formação dos práticos, } \\
\text { condições para a realização do serviço e } \\
\text { suspensão da habilitação de prático) } \\
\text { RE: Publicação das tarifas portuárias } \\
\text { (tasas portuarias) vigentes por cada } \\
\text { Autoridade Portuária, em conformidade } \\
\text { com a Lei de Portos }\end{array}$ & $\begin{array}{l}\text { RT: Lei } 9.537 \text { - Lei de Segurança do Tráfego } \\
\text { Aquaviário de } 1997 \text { - LESTA (segurança do tráfego } \\
\text { aquaviário, conceitos e definições relacionados à } \\
\text { navegação, atribuições da Autoridade Marítima, } \\
\text { competências do comandante, embarcação e } \\
\text { tripulação, serviço de praticagem, medidas } \\
\text { administrativas, penalidades). } \\
\text { Decreto } 2.596 \text { de } 1998 \text { - RLESTA (classificação } \\
\text { geral da navegação, atribuições da Autoridade } \\
\text { Marítima, infrações e penalidades, serviço de } \\
\text { praticagem). } \\
\text { NORMAM } 12 \text { (serviço de praticagem, regras para o } \\
\text { acesso e processo seletivo, certificação do prático, } \\
\text { organização e execução do serviço de praticagem, } \\
\text { deveres, manutenção da habilitação e motivos para } \\
\text { afastamento, normas para a determinação do número } \\
\text { de práticos por Zona de Praticagem (ZP), funções do } \\
\text { Conselho Nacional de Praticagem (CONAPRA), } \\
\text { detalhamento de lanchas de serviço (tripulações) e } \\
\text { equipamentos, atalaia, detalhamento das ZPs). } \\
\text { RE: Inexistente }\end{array}$ \\
\hline $\begin{array}{l}\text { Para que } \\
\text { governa }\end{array}$ & $\begin{array}{l}\text { RT: Monitorar o tráfego marítimo, } \\
\text { alcançando máxima eficiência na } \\
\text { segurança da vida humana no mar e na } \\
\text { prevenção contra a contaminação do meio } \\
\text { marinho. } \\
\text { RE: Garantir a segurança da navegação, } \\
\text { mantendo os custos e o nível dos serviços } \\
\text { de praticagem em patamares adequados }\end{array}$ & $\begin{array}{l}\text { RT: Regulamentar o serviço de praticagem, } \\
\text { estabelecer as zonas de Praticagem em que a } \\
\text { utilização do serviço é obrigatória e especificar as } \\
\text { embarcações dispensadas do serviço. } \\
\text { RE: Inexistente }\end{array}$ \\
\hline
\end{tabular}

RT: Regulação Técnica; RE: Regulação Econômica.

\subsection{Parametrização dos serviços de praticagem: aspectos operacionais}

Para a parametrização das operações de praticagem nos portos em análise, foram consultadas informações concedidas pelas Autoridades Portuárias e pelas Corporações de Práticos de Valência e de Barcelona, assim como estatísticas dos portos da Espanha disponibilizadas por Puertos del Estado. Para o porto de Santos, as informações tiveram como origem o Sistema de Desempenho Portuário (ANTAQ) e documentos disponíveis na Diretotia de Portos e Costas (DPC), como por exemplo as tabelas de Preços dos Serviços de Praticagem. A partir de tais dados, foi gerada a Tabela 1.

Tabela 1 - Dados comparativos dos serviços de praticagem em Valência, Barcelona e Santos

\begin{tabular}{l|rrrrr}
\hline Itens para comparação (2012) & Valência $(\boldsymbol{A})$ & Barcelona $(\boldsymbol{B})$ & Santos $(\boldsymbol{C})$ & $(\boldsymbol{C} / \boldsymbol{A})$ & $(\boldsymbol{C} / \boldsymbol{B})$ \\
\hline $\mathrm{N}^{\mathbf{0}}$ práticos $^{1}$ & 12 & 17 & 44 & $267 \%$ & $159 \%$ \\
$\mathrm{~N}^{\mathrm{o}}$ navios $^{2}$ & 6.935 & 7.768 & 5.355 & $-23 \%$ & $-31 \%$ \\
$\mathrm{AB}$ média $^{3}$ & 29.822 & 33.681 & 34.340 & $15 \%$ & $2 \%$ \\
$\mathrm{~N}^{\mathbf{0}}$ manobras $^{4}$ & 15.257 & 17.090 & 12.738 & $-17 \%$ & $-25 \%$ \\
Tempo médio de manobra (horas) $^{5}$ & 0,67 & 0,75 & 1,22 & $83 \%$ & $62 \%$ \\
Manobras por prático por ano $^{5}$ & 1.271 & 1.005 & 290 & $-77 \%$ & $-71 \%$
\end{tabular}


Manobras por prático por mês

Manobras por prático por dia

Horas de manobra por dia

Tarifa aplicável à $\mathrm{AB}$ média $(\mathrm{EUR})^{6,7}$

Receita bruta total (EUR)

Receita bruta por prático por ano (EUR)

Receita bruta por prático por mês (EUR)

Receita bruta por hora de manobra (EUR)

\begin{tabular}{rrrrr}
105,95 & 83,77 & 24,13 & $-77 \%$ & $-71 \%$ \\
3,48 & 2,75 & 0,79 & $-77 \%$ & $-71 \%$ \\
2,32 & 2,07 & 0,97 & $-58 \%$ & $-53 \%$ \\
410,34 & 617,98 & $5.925,51$ & $1344 \%$ & $859 \%$ \\
$6.260 .557,38$ & $10.561 .057,31$ & $75.479 .183,54$ & $1106 \%$ & $615 \%$ \\
$521.713,12$ & $621.238,67$ & $1.715 .435,99$ & $229 \%$ & $176 \%$ \\
$43.476,09$ & $51.769,89$ & $142.953,00$ & $229 \%$ & $176 \%$ \\
615,51 & 823,98 & $4.870,28$ & $691 \%$ & $491 \%$ \\
\hline
\end{tabular}

Fontes:

1 Corporaciones de Prácticos de Valencia e Barcelona; Diretoria de Portos e Costas (DPC)

2 Estatísticas de Puertos del Estado (Espanha); Sistema Desempenho Portuário (ANTAQ)

3 Estatísticas de Puertos del Estado (Espanha); Sistema Desempenho Portuário (ANTAQ)

4 Número de navios multiplicado por 2,2, considerando uma entrada, uma saída e $10 \%$ para troca de berços

5 Autoridades Portuárias de Valência e de Barcelona; Diretoria de Portos e Costas (DPC)

6 Autoridades Portuárias de Valência e de Barcelona; Tabelas de Preços dos Serviços de Praticagem (DPC)

7 Valores em Reais convertidos para Euros conforme a PPP (dez. 2012) de USD 1 = R\$ 1,9586 (IPEA) e USD $1=$ EUR

0,7829 (OCDE)

Em primeira análise dos dados da Tabela 1, verifica-se que o porto de Santos dispunha em 2012 de 44 práticos, o que corresponde, em média, ao triplo do empregado no porto de Valência e no porto de Barcelona. Cabe salientar que, recentemente, esse número foi ampliado para 65 , o que aumenta ainda mais a diferença com relação aos portos espanhóis estudados.

Em contrapartida, o número de navios atendidos e de manobras realizadas no Porto de Santos em 2012 foram menores do que os verificados nos portos espanhóis estudados. Apesar de o número de navios ser mais uniforme entre os portos do que o número de práticos, com uma diferença máxima de $31 \%$ verificada entre número de navios atendidos em Santos e em Barcelona, os dois fatores considerados conjuntamente, através do número de manobras por prático nos três portos, apresenta uma distorção ainda maior, conforme se pode observar na Figura 8, que apresenta o número de manobras por prático por dia, indicador que representa a produtividade diária por prático em cada um dos portos estudados.

Figura 8 - Comparação do número de manobras por prático por dia 




Essa distorção poderia ser explicada pelo tempo médio de manobra realizada pelos práticos, uma vez que as manobras em Santos duram em média 1,22 h contra uma média de $0,71 \mathrm{~h}$ para as manobras realizadas nos portos espanhóis estudados (Figura 9). No entanto, essa diferença de $72 \%$ entre o tempo médio de manobra no porto de Santos e a média dos tempos de manobra nos portos espanhóis não é suficiente para explicar o baixo índice de ocupação dos práticos verificado no porto brasileiro, já que os números de manobras por prático por dia em Valência e Barcelona são, respectivamente, $341 \%$ e $248 \%$ superiores aos verificados em Santos.

Figura 9 - Comparação em tempo médio de manobra em horas

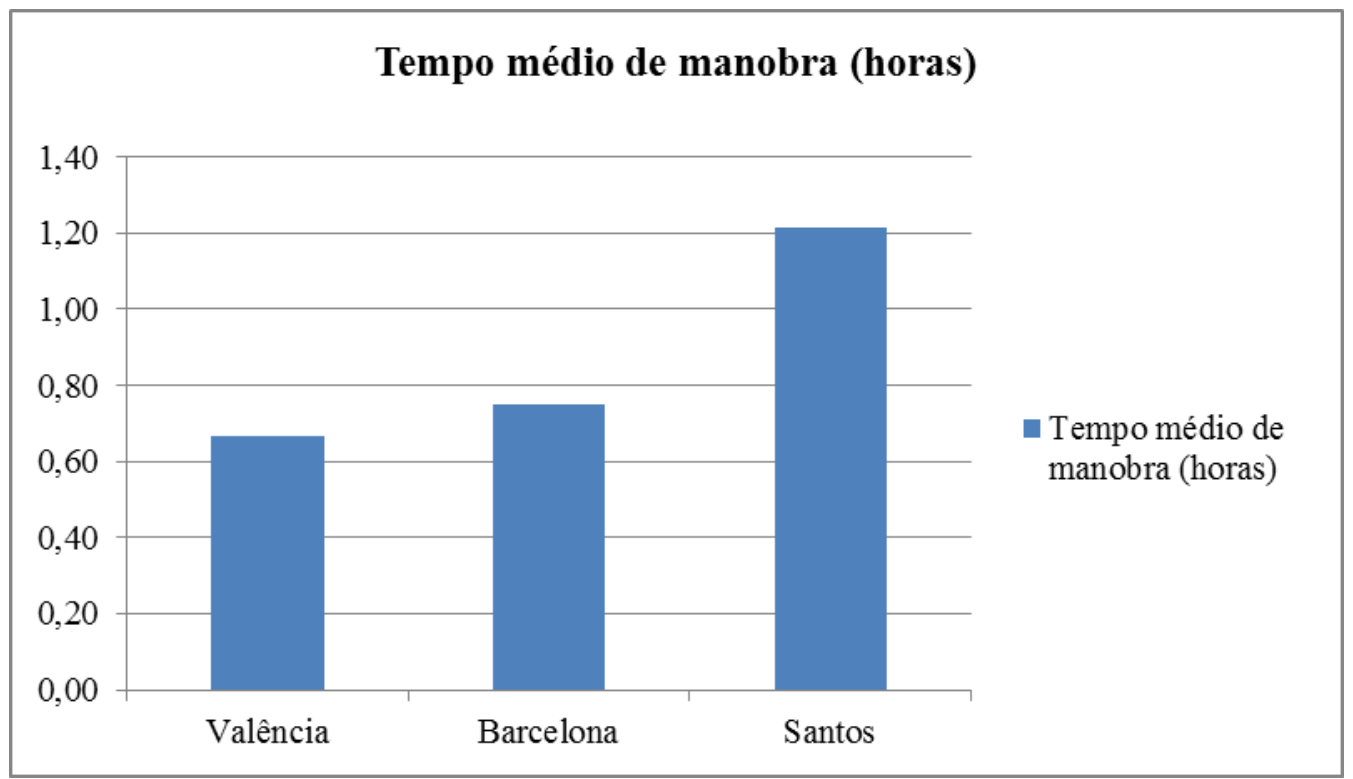

Quanto ao porte (arqueação bruta média) dos navios recebidos nesses portos durante o ano de 2012 (Figura 10), o porto de Santos se aproximou ao que foi apresentado no porto de Barcelona, resultando em uma diferença de apenas $2 \%$. Já entre os portos de Barcelona e de Valência, a diferença foi de $15 \%$. 
Figura 10 - Comparação em AB média



As tarifas aplicadas à arequeação bruta $(\mathrm{AB})$ média apresentaram a maior distorção entre os dados analisados (Figura 11). A tarifa aplicável à AB média no porto de Santos mostrou-se 1344\% superior à de Valência e 859\% maior do que a verificada em Barcelona.

Figura 11 - Comparação em tarifa aplicável à $\mathrm{AB}$ média em euros

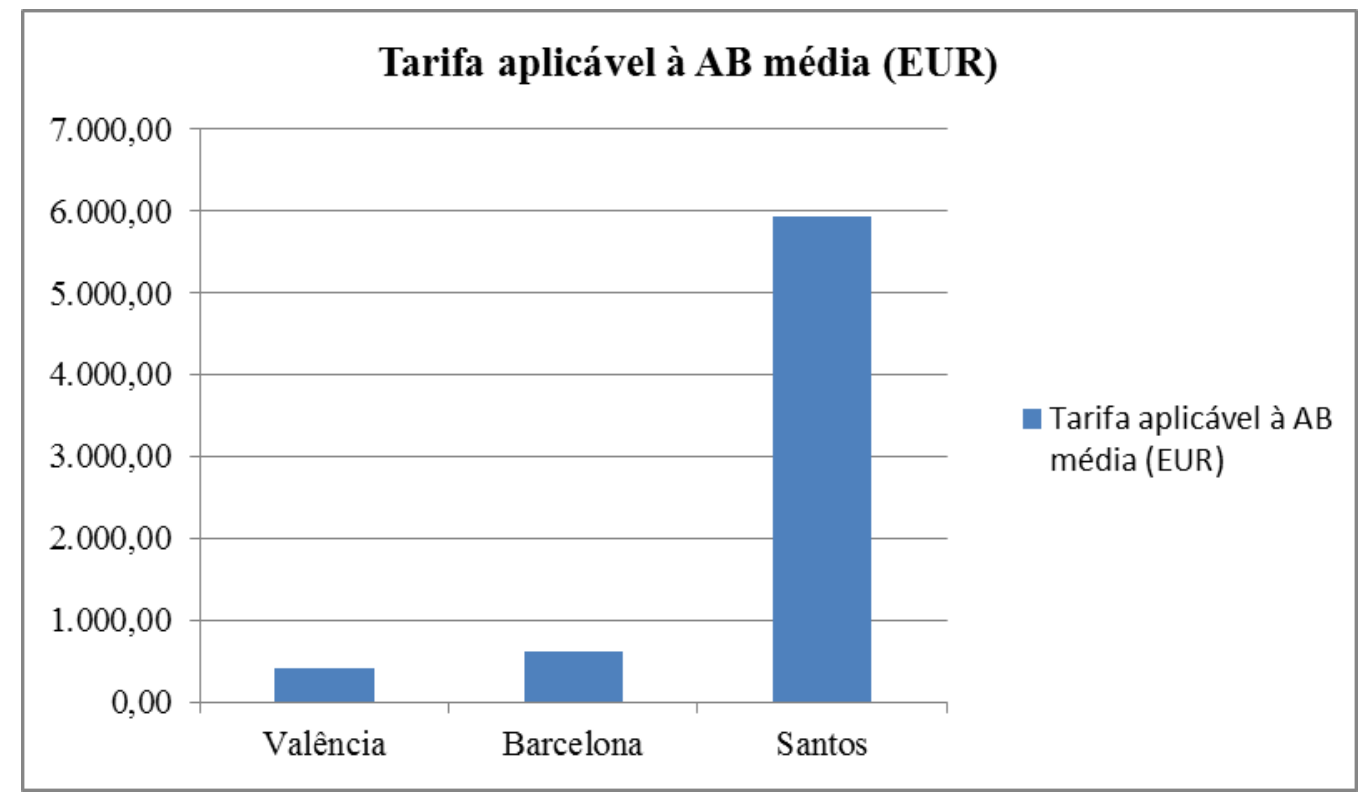

Consequentemente, a receita bruta anual (Figura 12) total em Santos foi a maior entre os três portos, com um valor aproximado de 75,5 milhões de euros. Em Barcelona e Valência, esse faturamento ficou em torno de 10,5 e 6 milhões de euros, respectivamente.

Figura 12 - Comparação em receita bruta total em euros 


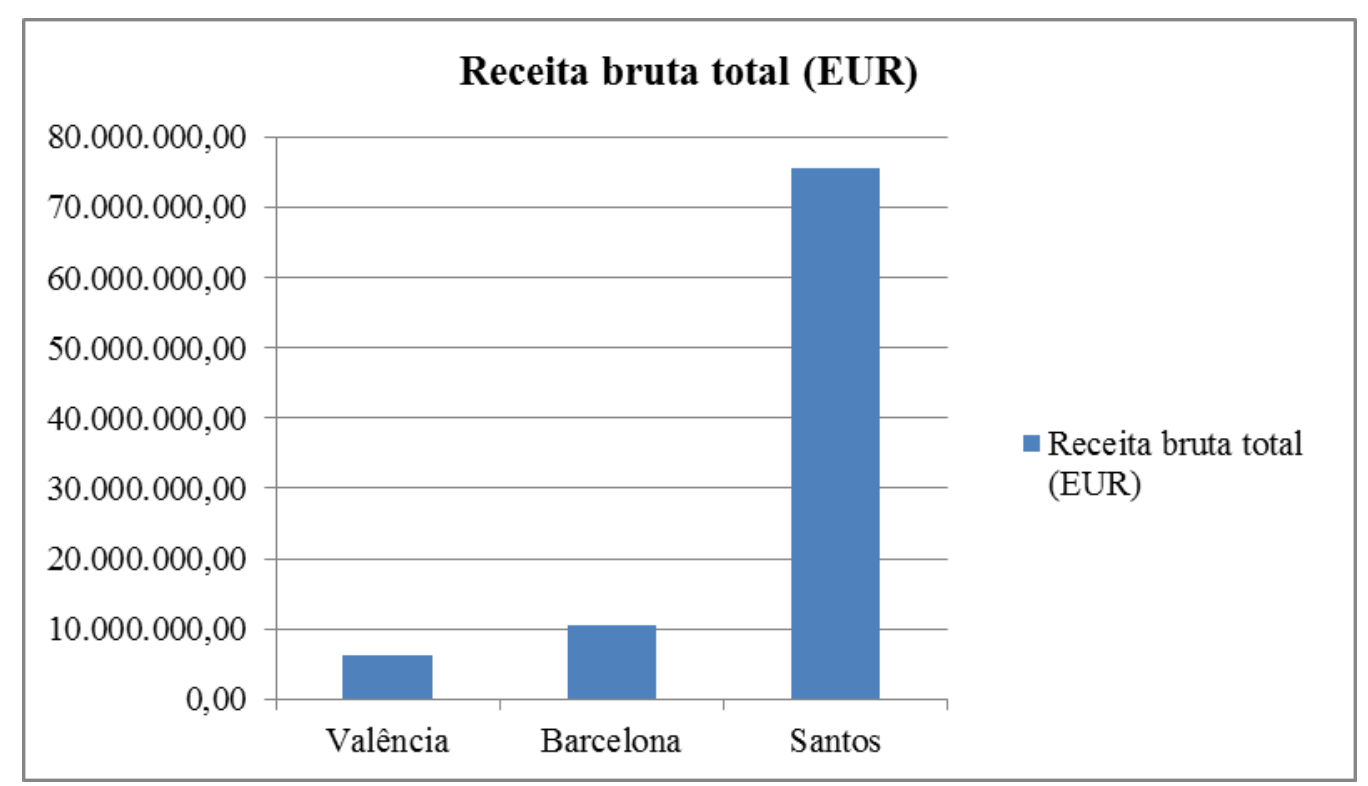

Calculando a receita bruta mensal por prático a partir de dados apresentados anteriormente, foi obtido um valor de aproximadamente 43 mil euros para os práticos de Valência, 52 mil euros para os de Barcelona e 143 mil euros para os de Santos (Figura 13).

Figura 13 - Comparação em receita bruta por prático por mês em euros



Percebe-se na Figura 13 que os práticos do porto de Santos apresentaram aproximadamente o triplo do faturamento mensal dos práticos dos portos espanhóis analisados. Essa diferença é resultado do modelo de governança dos serviços de praticagem existente no Brasil e se deve, em especial, à falta de regulação econômica do setor.

\section{Conclusões}

Existem no mundo diferentes tipos de portos, cujos desenvolvimentos ocorreram de distintas formas, condicionados por diferentes contextos históricos, tipos de demanda (mercadorias a serem 
transportadas e navios a serem atendidos) e modelos de gestão. Essa dissimilaridade, a qual gera dificuldade nos estudos que têm os portos como objeto, fez surgir na literatura uma série de modelos para a classificação de portos e para a análise da governança portuária. $\mathrm{O}$ estudo do modelo de governança portuária é importante porque é através dele que a governança é materializada e os resultados portuários são obtidos. Cabe salientar que, através desses modelos, pode ser analisada tanto a governança do porto como um todo quanto a governança de serviços portuários específicos, como é o caso da praticagem, visando analisar a relação entre o modelo de governança existente e a performance portuária decorrente do mesmo.

Neste estudo, foi aplicado o modelo proposto por Vieira, Kliemann Neto e Monfort-Mulinas (2013) à análise da governança dos serviços de praticagem nos portos de Santos (Brasil), Valência e Barcelona (Espanha). A contribuição do modelo aplicado para a análise dos serviços de praticagem nesses portos é evidenciada tanto por sua abrangência, uma vez que busca responder às quatro questões-chave relacionadas à governança de cadeias logístico-portuárias, quanto pela estruturação de uma lógica para a parametrização dos resultados da praticagem (preços cobrados pelos serviços e grau de eficiência das operações). Desse modo, o presente estudo mostrou-se contributivo para a análise da relação entre governança e performance em serviços portuários.

A aplicação do modelo aos portos de Santos, Valência e Barcelona evidenciou sua utilidade e adequação, revelando oportunidades de melhoria a serem consideradas no porto brasileiro. Nos portos espanhóis, verificou-se um melhor equilíbrio entre regulação técnica e econômica dos serviços de praticagem, e a análise desses serviços permitiu responder com clareza às quatro questões-chave propostas pelo modelo de Vieira, Kliemann Neto e Monfort-Mulinas (2013): i) Quem governa? ii) O que governa? iii) Como governa? e iv) Para que governa? Já no porto brasileiro verificou-se uma série de lacunas relacionadas com a regulação econômica do setor, o que tem ocasionado distorções nos preços dos serviços prestados e na eficiência das operações. Essas distorções são evidenciadas com clareza a partir da comparação com os portos espanhois estudados.

Cabe salientar, em contrapartida, a recente iniciativa de criação da Comissão Nacional para Assuntos de Praticagem (CNAP) e a intenção de se estabelecer uma regulação econômica para o setor, a qual, evidentemente, tem sido alvo de inúmeras críticas por parte da praticagem. Nesse contexto, o presente estudo contribui por corroborar as distorções que motivaram a criação da CNAP e por trazer à tona um aspecto ainda não suficientemente discutido no processo de regulação econômica dos serviços de praticagem: o grau de ocupação dos práticos/ eficiência do sistema.

Cabe salientar que, a partir da verificação da aplicabilidade do modelo à análise dos serviços de praticagem, pode-se inferir que o modelo é aplicável não só a esse tipo de serviço, mas também a outros tipos de serviços portuários, tais como movimentação e armazenagem, rebocadores, etc. Deve-se considerar, também, que o modelo é útil como uma 'estrutura de referência para a análise 
da governança' e pode ser aplicado em três distintas fases de um processo de reforma portuária: i) ambiente pré-reforma (diagnóstico da situação encontrada); ii) reforma portuária (ajustes no modelo de governança); e iii) ambiente pós-reforma (resultado do novo modelo de governança).

Por outro lado, embora contributivo, devem-se considerar algumas limitações do presente estudo. Em primeiro lugar, deve-se entender o modelo de governança utilizado não como um modelo prescritivo que defina como deva ser feita a governança dos serviços portuários, mas sim como uma estrutura que facilita sua análise. Outro ponto a salientar é a possível dificuldade para coletar dados necessários a aplicação do modelo em suas diferentes dimensões e fases. Essa foi uma limitação importante, principalmente no caso brasileiro, uma vez que, desde a criação da CNAP, tem sido difícil obter dados de operações de praticagem nos portos brasileiros, mesmo considerando os relatórios de Consultas Públicas já publicados. Por esse motivo, o estudo foi feito com base em dados de 2002, o que o torna menos atualizado. Outro ponto a destacar é a dificuldade de isolar fatores e relacionar estatisticamente governança e performance dos serviços portuários, uma vez que o desempenho em tais serviços não depende exclusivamente da governança, sendo influenciado por variados aspectos, muitos deles de natureza qualitativa.

Alternativamente ao modelo utilizado, como sugestão para estudos futuros, pode ser realizada a análise da governança dos serviços de praticagem a partir de uma abordagem de economia industrial, considerando-se a alocação dos direitos de decisão; a mensuração da performance; e a avaliação do sistema de recompensa. Essa abordagem poderia ser complementar à utilizada no presente estudo, auxiliando na análise de cada uma das dimensões de governança apresentadas e no processo de regulação dos serviços de praticagem como um todo.

\begin{abstract}
Seaports are key elements in the global shipping network and they are responsible for land-sea interface. For appropriate port management, it is essential to understand the harbour in a broader sense, considering the different roles associated with port logistics chain and the wide range of port activities. Among such activities, there are the maritime services prior to ship berthing and, particularly, maritime pilotage services, which are essential to ensure safety and efficiency for port operations and have influence on the cost of vessel calls. In recent years, it has been discussed the suitability of the Brazilian maritime pilotage model and its conformance with existing models in other countries. In this regard, an important issue concerns the relationship between the pilotage model adopted and the results achieved, specifically regarding to prices of services and system usage rate. In this context, the present study aims to compare the maritime pilotage services in the ports of Santos, Valencia and Barcelona, based on a conceptual model of analysis of port governance and following a qualitative and exploratory approach. The results indicate that the lack of economic regulation of pilotage services in Brazil has led to high pilotage prices and low productivity of the maritime pilotage in Santos.
\end{abstract}

Key-words: Governance; Port Services; Pilotage; Brazilian and Spanish ports. 


\section{Referências}

AGÊNCIA NACIONAL DE TRANSPORTE AQUIAVIÁRIO - ANTAQ. Indicadores de Desempenho Portuário. Sistema Permanente de Acompanhamento de Preços e Desempenho Operacional dos Serviços Portuários. Cartilha de Orientação. Fevereiro 2003. Disponível em: http://www.antaq.gov.br/portal/DesempenhoPortuario/Cartilha.pdf. Acesso em: 21.mar.2014.

BALTAZAR, R.; BROOKS, M. R. Port governance, devolution and the Matching Framework: a configuration theory approach. Research in Transportation Economics, v. 17, n. 1, p. 379-403, 2006. cross ref

BEAMON, B. Supply chain design and analysis: Models and methods. International Journal of Production Economics, v. 55, n. 3, p. 281-294, 1998. crossref

BRASIL. Marinha do Brasil. Diretoria de Portos e Costas. Normas da Autoridade Marítima para o Serviço de Praticagem. NORMAM-12/DPC. Site institucional. Disponível em:

<https://www.dpc.mar.mil.br/sites/default/files/normam12_0.pdf> . Acesso em: 12.dez.2014.

BRASIL. Presidência da República. Casa Civil. Subchefia para Assuntos Jurídicos. Lei n 9.537 de 11 de dezembro de 1997. Lei de Segurança do Tráfego Aquaviário (LESTA).

BRASIL. Presidência da República. Casa Civil. Subchefia para Assuntos Jurídicos. Decreto no 2596, de 18 de maio de 1998. Regulamento da Lei de Segurança do Tráfego Aquaviário (RLESTA).

BROOKS, M. R. Port devolution and governance in Canada. Research in Transportation Economics, v. 17, n. 1, p. 237-257, 2006. crossref

BROOKS, M. R.; CULLINANE, K. Governance models defined. Research in Transportation Economics, v. 17, n. 1, p. $405-435,2006$. crossref

BROOKS, M. R.; PALLIS, A. A. Assessing port governance models: process and performance components. Maritime Policy and Management, v. 35, n. 4, p. 411-432, 2008.

BUSSINGER, F. Reformas e Regulação Portuária. São Paulo: IPEA - Instituto de Pesquisa Econômica Aplicada, 1998.

Centro de estudos em Gestão Naval - GEGN. Escola Politécnica da Universidade de São Paulo. Análise de estrutura operacional, de custos e recursos de uma associação de Praticagem no Brasil e comparação do desempenho e dos modelos com casos internacionais. Junho de 2008.

CERVO, A. L.; BERVIAN, P. A. Metodologia científica. 5. ed. São Paulo: Prentice Hall, 2002.

CONSELHO NACIONAL DE PRATICAGEM - CONAPRA. Site institucional. Disponível em:

<http://www.conapra.org.br>. Acesso em 04.jul.2012.

CULLINANE, K.; WANG, T. F. Port governance in China. Research in Transportation Economics, v. 17, n. 1, p. 331-356, 2006. crossref

CULLINANE, K.; YAP, W. Y.; LAM, J. S. L. The port of Singapore and its governance structure. Research in Transportation Economics, v. 17, n. 1, p. 285-310, 2006. crossref

DE LANGEN, P. W. Governance in Seaport Clusters. Maritime Economics and Logistics, v. 6, n. 1, p. 141-156, 2004. crossref

DE LANGEN, P. W. Stakeholders, conflicting interests and governance in port clusters. Research in Transportation Economics, v. 17, n. 1, p. 457-477, 2006. crossref

DE LANGEN, P. W.; NIJDAM, M. N.; van der HORST, M. R. Port performance indicators in ports. Journal of Maritime Research, v. 4, n. 1, p.23-36, 2007.

DE LANGEN, P. W.; van der LUGT, L. M. Governance structures of Port Authorities in the Netherlands. Research in Transportation Economics, v. 17, n. 1, p. 109-137, 2006 crossref. 
DE LANGEN, P. W.; van der LUGT, L. M.; JOOST, H. A. A stylised container port hierarchy: a theoretical and empirical exploration. International Association of Maritime Economists. IAME Panama 2002 Conference. Proceedings... Panama City, 2002. Disponível em:

<http://www.cepal.org/usi/perfil/iame_papers/proceedings/Langen_et_al.doc>. Acesso em: 24 nov. 2011.

DEBRIE, J.; GOUVERNAL, E.; SLACK, B. Port devolution revisited: the case of regional ports and the role of lower tier governments. Journal of Transport Geography, v. 15, n.1, p. 455-464, 2007. crossref

FAWCETT, J. A. Port governance and privatization in the United States: public ownership and private operation. Research in Transportation Economics, v. 17, n. 1, p. 207-235, 2006.

FLÄMIG, H.; HESSE, M. Placing dryports. Port regionalization as a planning challenge - The case of Hamburg, Germany, and the Süderelbe. Research in Transportation Economics, v. 33, n. 1, p. 42-50, 2011. crossref

GEIGER, A. Modelo de governança para apoiar a inserção competitiva de arranjos produtivos locais em cadeias globais de valor. Tese de Doutorado. Programa de Pós-Graduação em Engenharia de Produção (PPGEP). Universidade Federal do Rio Grande do Sul (UFRGS). Porto Alegre, 2009.

GIL, A. C. Métodos e Técnicas de Pesquisa Social. 5. ed. São Paulo: Atlas, 1999.

HELLEBUSCH, S. Don't read research by the numbers. Marketing News, v. 34, n. 19, p. 25, 2000.

MARCONI, M. A.; LAKATOS, E. M. Técnicas de pesquisa: planejamento e execução de pesquisas, elaboração, análise e interpretação de dados. 5. ed. São Paulo: Atlas, 2002.

MEERSMAN, H.; VAN DE VOORDE, E.; VANELSLANDER, T. Fighting for money, investments and capacity: port governance and devolution in Belgium. Research in Transportation Economics, v. 17, n. 1, p. 85-107, 2006.

crossref

MILAN, G. S.; VIEIRA, G. B. B. Proposição de um modelo conceitual em torno da prática da governança em cadeias logístico-portuárias. Revista Gestão Industrial, v. 7, n. 4, p. 154-174, 2011.

MONFORT-MULINAS, A.; MONTERDE HIGUERO, N.; SAPIÑA GARCÍA, R.; MARTÍN SOBERÓN, A. M; CALDUCH VERDUCH, D.; SOUZA, P V. G. La terminal portuaria de contenedores como sistema nodal en la cadena logística. 2. ed. Valência: Fundación Valenciaport, 2012.

PALLIS, A. A. Maritime Transport: The Greek Paradigm. Research in Transportation Economics, v. 21, n. 1, p. 343-382, 2007. crossref

PALLIS, A. A. Port governance in Greece. Research in Transportation Economics, v. 17, n. 1, p. 155-169, 2006. crossref

SAMPIERI, R. H.; COLlADO, C. F.; LUCIO, P. B. Metodologia de Pesquisa. 3. ed. São Paulo: MacGraw-Hill, 2006.

SILVA, E. L.; MENEZES, E. M. Metodologia da Pesquisa e Elaboração de Dissertação. 4. ed. Florianópolis: Universidade Federal de Santa Catarina (UFSC), 2005. Disponível em:

<https://projetos.inf.ufsc.br/arquivos/Metodologia_de_pesquisa_e_elaboracao_de_teses_e_dissertacoes_4ed.pdf> Acesso em: 21.mar.2014.

SKINNER, D.; TAGG, C.; HOLLOWAY, J. Managers and research: the pros and cons of qualitative approaches. Management Learning, v. 31, n. 2, p. 163-179, 2000. crossref

United Nations Conference on Trade and Development - UNCTAD. Review of Maritime Transport 2011. Report by the UNCTAD Secretariat. United Nations: New York and Geneva, 2011. Disponível em:

<http://archive.unctad.org/Templates/WebFlyer.asp?intItemID=6134\&lang=1>. Acesso em: 09.abr.2012.

van der LUGT, L.; DE LANGEN, P. Port authority strategy: beyond the landlord. In: Proceedings of International Association for Maritime Economists (IAME). Athens, Greece, July 2007. Disponível em: <www.porteconomics.nl/docs/port_authority.pdf>. Acesso em: 07 abr. 2011.

VIEIRA, G. B. B.; KLIEMANN NETO, F. J. MONFORT-MULINAS, A. O modelo de governança portuária revisitado: Uma contribuição para o processo de reforma portuária. Revista Espacios, v. 34, n. 10, p. 6, 2013. 
WANG, J. J.; NG, A. K. Y.; OLIVIER, D. Port governance in China: a review of policies in an era of internationalizing port management practices. Transport Policy, v. 11, n. 1, p. 237-250, 2004. crossref

WORLD BANK. World Bank Port Reform Toolkit. World Bank Transport Division, 2001. Disponível em:

<http://siteresources.worldbank.org/INTPRAL/Resources/338897-1117197012403/overview_bookmarks.pdf>. Acesso em: 10.mai.2012.

WORLD TRADE ORGANIZATION - WTO. International Trade Statistics 2011. Disponível em:

<http://www.wto.org/english/res_e/statis_e/its2011_e/its11_toc_e.htm.> Acesso em: 09.abr.2012.

\section{Dados dos autores}

Nome completo: Guilherme Bergmann Borges Vieira

Filiação institucional: Universidade de Caxias do Sul (UCS) e Universidade Federal do Rio Grande do Sul (UFRGS)

Departamento: Centro de Ciências Sociais (CCSO)

Função ou cargo ocupado: Professor pesquisador na Universidade de Caxias do Sul (UCS) e pósdoutorando no Programa de Pós-Graduação em Engenharia de Produção da Universidade Federal do Rio Grande do Sul (PPGEP/ UFRGS)

Endereço completo para correspondência: Rua Francisco Getúlio Vargas, 1130 - CEP 95070-560 Caxias do Sul - RS

Telefones para contato: (54) 3218-2100 / (51) 99448504

e-mail: gbbvieir@ucs.br

Nome completo: Luiz Afonso dos Santos Senna

Filiação institucional: Universidade Federal do Rio Grande do Sul (UFRGS)

Departamento: Departamento de Engenharia de Produção e Transportes (DEPROT)

Função ou cargo ocupado: Professor do Programa de Pós-Graduação em Engenharia de Produção (PPGEP/ UFRGS)

Endereço completo para correspondência: Av. Osvaldo Aranha, 99 - $5^{\circ}$ Andar - Bairro Bom Fim -

Porto Alegre - RS - CEP: 90035-190

Telefone para contato: (51) 3308-3491

e-mail: lsenna@producao.ufrgs.br

\section{Nome completo: Francisco José Kliemann Neto}

Filiação institucional: Universidade Federal do Rio Grande do Sul (UFRGS)

Departamento: Departamento de Engenharia de Produção e Transportes (DEPROT)

Função ou cargo ocupado: Professor do Programa de Pós-Graduação em Engenharia de Produção (PPGEP/ UFRGS) 
Endereço completo para correspondência: Av. Osvaldo Aranha, 99 - $5^{\circ}$ Andar - Bairro Bom Fim Porto Alegre - RS - CEP: 90035-190

Telefone para contato: (51) 3308-3491

e-mail: kliemann@producao.ufrgs.br

Nome completo: Rafael Mozart da Silva

Filiação institucional: Universidade Federal do Rio Grande do Sul (UFRGS)

Departamento: Laboratório de Sistemas de Transportes (LASTRAN)

Função ou cargo ocupado: Pesquisador

Endereço completo para correspondência: Av. Osvaldo Aranha, 99 - 5 Andar - Bairro Bom Fim -

Porto Alegre - RS - CEP: 90035-190

Telefone para contato: (51) 3308-3596

e-mail: rafmozart@terra.com.br

Nome completo: Priscila Coutinho Costa

Filiação institucional: Universidade Federal do Rio Grande do Sul

Departamento: Departamento de Engenharia de Produção e Transportes

Função ou cargo ocupado: Graduanda do Curso de Engenharia Civil

Endereço completo para correspondência: Av. Osvaldo Aranha, 99 - 5 Andar - Bairro Bom Fim Porto Alegre - RS - CEP: 90035-190

Telefone para contato: (51) 3308-3491

e-mail: priscila.costa@ufrgs.br

Submetido em: 16-12-2014

Aceito em: 07- 05-2015 